\title{
False positive and false negative errors in the design and implementation of agri- environmental policies: a case study on water quality and agricultural nutrients
}

Article

Accepted Version

Creative Commons: Attribution-Noncommercial-No Derivative Works 4.0

Psaltopoulos, D., Wade, A., Skuras, D., Kernan, M., Tyllianakis, E. and Erlandsson, M. (2017) False positive and false negative errors in the design and implementation of agrienvironmental policies: a case study on water quality and agricultural nutrients. Science of the Total Environment, 575. pp. 1087-1099. ISSN 0048-9697 doi:

https://doi.org/10.1016/j.scitotenv.2016.09.181 Available at https://centaur.reading.ac.uk/67069/

It is advisable to refer to the publisher's version if you intend to cite from the work. See Guidance on citing.

To link to this article DOI: http://dx.doi.org/10.1016/j.scitotenv.2016.09.181

Publisher: Elsevier

All outputs in CentAUR are protected by Intellectual Property Rights law, including copyright law. Copyright and IPR is retained by the creators or other copyright holders. Terms and conditions for use of this material are defined in the End User Agreement. 


\section{www.reading.ac.uk/centaur}

\section{CentAUR}

Central Archive at the University of Reading

Reading's research outputs online 


\title{
False Positive and False Negative Errors in the Design and Implementation of Agri- environmental Policies: A Case Study on Water Quality and Agricultural Nutrients
}

\author{
Demetrios Psaltopoulos ${ }^{1}$, Andrew J. Wade ${ }^{2}$, Dimitris Skuras ${ }^{3}$, Martin Kernan ${ }^{4}$, \\ Emmanouil Tyllianakis ${ }^{5}$ and Martin Erlandsson ${ }^{6}$ \\ ${ }^{1}$ Professor, Department of Economics, University of Patras, University Campus, Rio, 26504
} Greece; email: skuras@econ.upatras.gr

${ }^{2}$ Professor, Department of Geography and Environmental Science, University of Reading, Whiteknights, , Reading, RG6 6DW, UK;

${ }^{3}$ Professor, Department of Economics, University of Patras, University Campus, Rio, 26504 Greece; email: dempsa@upatras.gr

${ }^{4}$ Senior Project Manager, CBEC Eco-Engineering UK Ltd, The Green House, Beechwood Park North, Inverness, IV2 3BL, UK; email: m.kernan@cbecoeng.co.uk

${ }^{5}$ Ph.D Candidate, Department of Economics, University of Patras, University Campus, Rio, 26504 Greece; email: etyllianakis@upatras.gr

6 Research Fellow, Department of Earth Sciences, Uppsala University, Sweden; email: martin.erlandsson@geo.uu.se

\section{Acknowledgement}

This work was carried out as part of the REFRESH FP7 Project: Adaptive Strategies to Mitigate the Impacts of Climate Change on European Freshwater Ecosystems, funded by EU Seventh Framework Program (Grant Agreement 244121): www.refresh.ucl.ac.uk. 


\begin{abstract}
When designing and implementing agri-environmental policies to reduce nutrient loss, action programmes may falsely address areas where the nutrient issue from agricultural activity is not currently important and is not likely to become so in the future (a false positive), or may fail to address areas where the agricultural nutrient issue is currently important or may likely become so in the future (a false negative). Based on a case study of the Louros watershed in Greece, this work identifies database and modelling sources of false positives and negatives and proposes a decision making process aimed at minimizing the possibility of committing such errors. The baseline is well simulated and shows that the Louro's watershed falls behind a Good Environmental Status, at least marginally. Simulated mitigation measures show that the river's status can be upgraded to "Good", at least as concerns nitrates and ammonium. Simulated climate change does not seem to exert an important positive or negative effect. Land use changes forecasting considerably less cultivated area have a significant effect on Total Phosphorous but not on nitrates or ammonium concentrations. The non-linearity between nutrient disposition (inputs) and nutrient concentration in downstream water bodies (output) and the many factors that affect the nutrient disposition-transportation-concentration chain, highlights the importance of simulating the effects of mitigation actions and of future climate and land use changes before adopting and establishing agri-environmental measures.
\end{abstract}




\section{A Decision Making Process for Rejecting False Positives and False Negatives}

in the Design and Implementation of Agri-environmental Policies

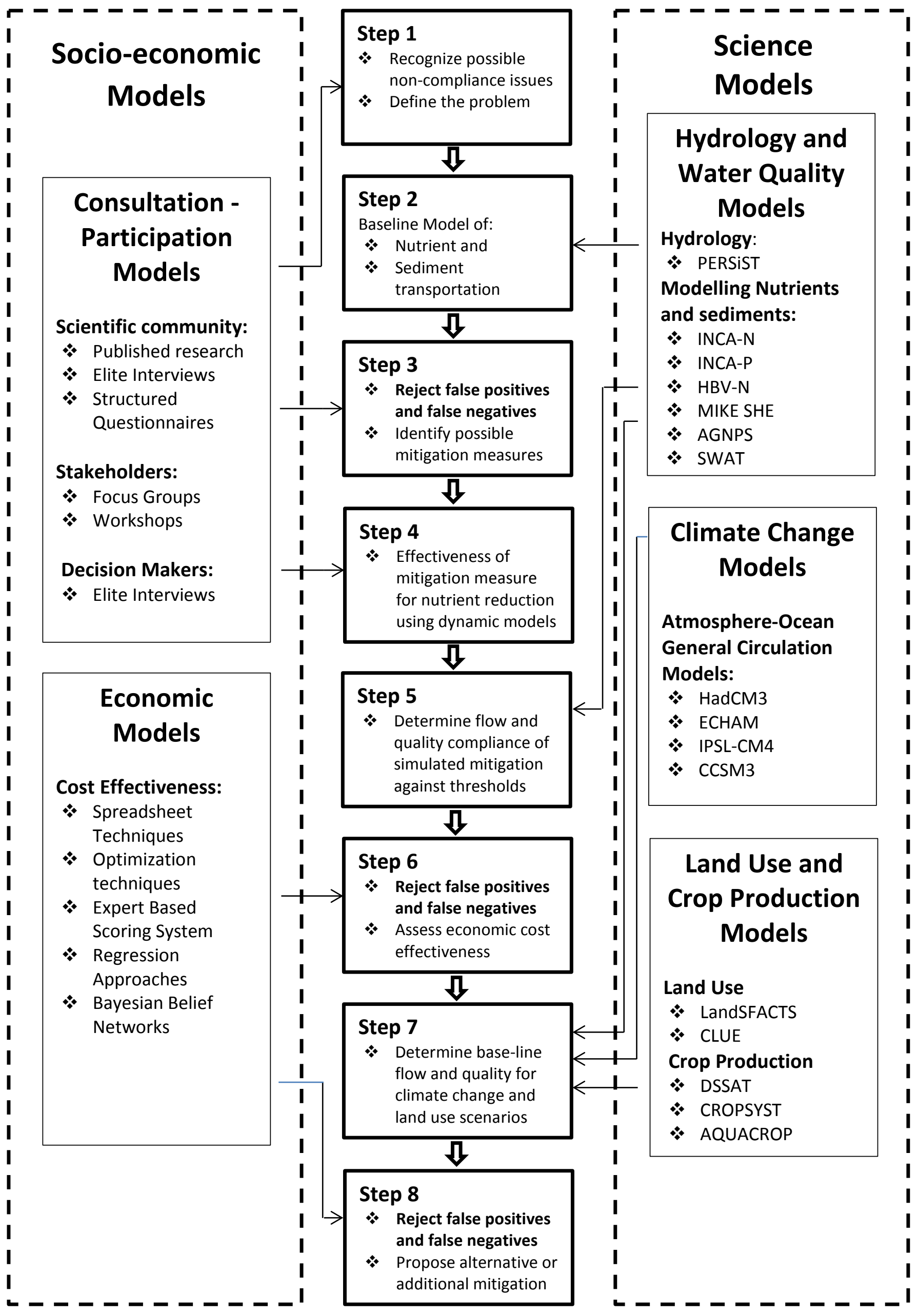


Significant amount of public funds are devoted to EU's agri-environment policy and commitments undertaken by farmers are long term.

It is important to assure policy decision makers that such funds are directed to the areas in need and in a cost effective way

False positive decisions emerge when agricultural activity is falsely acknowledged as the major nutrient supplier or when mitigation measures are falsely assumed to uphold nutrient supply

We advocate a decision making process integrating science and social science models to protect policy design from committing false positives or false negatives

The Louros watershed in Greece is used as a case-study for examining the economic loss under a false positive decision

Climate and land use change can alter the effects of agriculture on water bodies in the future and policy should be prepared to confront this evolution 
1 False Positive and False Negative Errors in the Design and Implementation of Agri2 environmental Policies: A Case Study on Water Quality and Agricultural Nutrients

\section{Introduction}

Mineral fertilizers and livestock manures are the main sources of nutrients which, very often, are out of balance with land availability and in excess of crop needs.

7 This imbalance creates a surplus of nutrients, some of which is lost to water, mainly as nitrates and phosphates, and air mainly as ammonia and nitrogen oxides

9 (MacDonald et al., 2011; Fowler et al., 2015). As a result, eutrophication due to nutrient emission from agriculture and urban and industrial runoff is a major threat to wetland ecosystem health (Verhoeven et al., 2006). In the European Union (EU), agrienvironment measures (AEM) constitute one of the main types of policy response for meeting society's demand for environmental outcomes provided by agriculture.

The application of AEM is compulsory at the Member State level, but optional at the farmer level. Consequently, the design of AEM is foreseen to meet public demand for environmental goods under the budgetary constraint of payments to farmers that aim to cover the costs incurred and income forgone as resulting from voluntary environmental commitments. The involvement of farmers is usually medium to long-term with a minimum participation of five years. The agrienvironment policy has an embedded "Nitrates" component in its mandatory part, i.e. the Nitrates Directive (EEC, 1991), and implements action programmes for controlling nutrients balance that are voluntary for farmers within the so called Nitrates

23 Vulnerable Zones (NVZs) and through the national and regional Rural Development Programmes (RDPs). The Nitrates Directive is an important building block of the wider 
the Water Framework (WFD) and the Habitats and Birds Directives. Over the years, agri-environment policy has emerged as one of the most important elements of the Common Agricultural Policy (CAP) in terms of its budgetary size and the proportion of participating farmers and farmland.

The effectiveness of AEMs to enhance biodiversity (Batáry et al., 2015; Kleijn and Sutherland, 2003) and protect aquatic environments from agricultural pollution has been reviewed very extensively, has been questioned and criticized (Grinsven et al., 2016; Buckley et al., 2016; Matzdorf and Lorenz, 2010; Randall et al., 2015). The results are disparate mainly due to the plethora of applied measures, the heterogeneity in the application agroecosystems and their baseline status, the variability in set targets and the way these targets are monitored. Decision making for the adoption and establishment of AEMs targeting the reduction of nutrient concentration in water is implemented, very frequently, without a comprehensive and integrated plan. For example, AEM decision makers may be unable to control for nonagricultural nutrient contributing activities, industrial or municipal, which are beyond their institutional jurisdiction. As a result, AEM decision makers tend to set program targets on inputs (quantities of mineral fertilizers, manure or irrigation water) rather than on downstream chemical water quality or environmental status. Consequently, an AEM can be considered to be very effective because it managed to reduced inputs to the targeted level when, in reality, the AEM had marginal or no effect in reducing nutrient loads downstream.

In decision-making, a false positive, known in statistics as Type I error, refers to the situation where the presence of a condition is assumed when in reality there is not such a situation. A false negative, known in statistics as Type II error, refers to the 
situation where no presence of a condition is assumed when in reality there is one. As such, the words "positive" and "negative" correspond to the answers "yes" or "no" to the question "is upstream agricultural activity responsible for downstream pollution?". In this sense, a false positive coincides with "yes (positive) agriculture is responsible for downstream pollution" when in reality this is not true (false). Correspondingly, a false negative decision is committed when answering "no (negative) agriculture is not responsible for downstream pollution" when in reality it is responsible (false). In addition to the current situation, action programmes should consider whether the nutrients issue is likely to increase or decrease in the future. In this case the decision question "is upstream agricultural activity likely to become responsible for downstream pollution in the next 7-10 years?" can lead to false positives if action programmes address areas where the nutrients issue is neither currently nor in the future likely to become important. In this context, false negatives emerge when action programmes address areas where the nutrients issue is currently very important and may likely remain so in the future (false negative). In any case, an informative forecast of the future effects of agriculture on the environment can alert policy to be ready to establish programmes or to respond by modifying the incentives provided in existing programmes.

The aim of this paper is to propose an integrated decision making framework for designing and establishing AEMs targeting nutrient reduction. This decision making framework reduces the risk of committing false positives and wasting financial resources or the risk of committing false negatives and not protecting the environment. Section 2 of this work, briefly reviews the sources contributing to the risk of committing either false positives or false negatives and sketches the proposed 
decision making processes. Section 3 presents the Greek case study of the Louros watershed and describes the methods, information sources and underlying assumptions in the derivation of the various alternative scenarios associated with the adoption of agri-environment programmes, CAP reform and climate changes affecting both the hydrology of the catchment and the nutrient uptake rate of plants. Section 4 presents the results of the analysis, while section 5 concludes and draws policy recommendations for a safer decision making process during the design and implementation phases of AEMs.

\section{Sources of False Positives and Negatives in the Design of Agri-environmental}

\section{Policy}

Mandatory and voluntary AEM aim, amongst others, to reduce nutrient concentrations in downstream rivers, lakes and wetlands. Most frequently, such measures directly target nutrient deposition (inputs) to land by setting maximum application rates. For example, the Nitrates Directive states that the amount of livestock manure applied on agricultural land each year, including that applied by animals themselves, should not exceed a maximum of $170 \mathrm{~kg}$ of nitrogen per hectare.

Other measures attempt to manage nutrients on the field, by promoting favourable farm practices such as crop rotation systems, while others aim at restricting leaching of nutrients from the field, through (e.g.) the maintenance of buffer strips. The design and implementation of agri-environment action programmes for nutrient control is based on information about nutrient deposition from agricultural and livestock activity measured in $\mathrm{kg}$ per hectare and the concentration of nutrients in surface and groundwater measured in $\mathrm{mg} / \mathrm{L}$. This practice of setting policy targets presumes a 
direct relationship between nutrient deposition on the field and downstream nutrient concentration. As such, it fails to take account of the static abiotic environment (geology and soil) and the dynamics of human activity and climate change, as well as of the changing and fluctuating water supply. Thus, we should not presume a linear and static relationship between deposition and concentration on which to build solid and robust $A E M$.

Figure 1 below attempts to sketch how false positives and false negatives may be generated in agri-environmental policy-making. The upper part of the diagram provides a coarse picture of the nutrient deposition-leaching-transportationconcentration process and how this process is influenced by abiotic, biotic, human activity and climate change factors. Under abiotic factors we refer to those physical processes pertinent to the geology, topography, soil physical and chemical properties. Under biotic factors, we refer to the whole range of sources that contribute to nutrient deposition such as land uses other than agriculture and animal activity other than livestock and/or grazing. Under human activity factors, we refer to agriculture and other activities contributing nutrients and including municipal and industrial sources coming from septic tanks or other devices of establishments that are not connected to municipal wastewater networks, animal wastes, food processing, etc. In addition, activities other than agriculture, may have an impact on the hydrology and especially on the quantity and frequency of water provided to water courses. Beyond irrigation and its corresponding drainage networks, examples include water extraction for municipal and industrial uses and sometimes small or large scale energy production from hydro electrical power plants. Finally, climate and especially temperature and 
runoff are important factors determining nutrient cycling and transport (Howarth et

122 al., 2012).

The relationship between agricultural inputs and instream nutrient concentrations is not a simple one, for example because of a large groundwater store that may act as nutrient reservoir or because water flows may change, or plant uptake may increase, or land use may change (Jackson et al., 2008; Howden et al., 2010). Thus,

127 the underlying relationship between nutrient deposition by agriculture and its impact on nutrient concentration in downstream water bodies may be important (yespositive) or not (no-negative). However, without an integrated approach modelling the relationship between nutrient input and instream concentrations there will be uncertainty as to whether the policy can address the input-output relationship accurately, and therefore avoid the risk of false positives and false negatives. Table 1 provides an indicative list of false positive or negative decisions along with connotative reasons causing these deceptive decisions. A similar table may be generated if dynamic changes caused by land use and climate change are taken into account. In 136 this context, dynamics may generate an agricultural pollution issue in areas that currently have not such an issue and vice versa. In this work we focus on two broad areas within the policy design process 139 which may contribute to the generation of false positives and false negatives:

- Appropriate baseline monitoring and modelling of the nutrient depositionconcentration function and the resultant baseline abatement function measured in terms of nutrient concentration in the water downstream and, 
- Forecasting and incorporation of changes resultant from human activity and climate change and the resultant dynamic abatement function again measured in terms of nutrient concentration in the water downstream

Taking into account the long-term horizon for implementing an agri-environment programme, policy design, and especially baseline modelling, should consider dynamic changes that may considerably alter the initial conditions that lead to the adoption or the rejection of an agri-environment programme in a specific area. For example, within a seven year agri-environment planning horizon, several changes may occur in land use, in agricultural production or/and even climatic conditions. Land use changes may be instigated by agricultural policy changes such as the CAP, which may lead to the abandonment of agricultural production or to the drastic change in the adoption of cultivations with different nutrient applications (Barbayiannis et al., 2011). One vivid example is the decoupling of Pillar 1 subsidies, which in some EU areas, has induced the abandonment of several cultivations or the shift to other crops, including nitrogen fixing legumes and the consequent reduction in nitrogen deposition. At the same time other, economy-wide developments, may affect (increase) agricultural input prices resulting to a rationalization and the consequent reduction of nutrient deposition.

In conventional policy design, targets are set on deposition, assuming that a proportional reduction will be achieved in the corresponding concentration of nutrients. The Nitrates Directive and several other EU, national and regional policies set such targets. This approach promotes "one-size fits all" policy and fails to take account of the aforementioned specificities of the environment and of human activity in the target-area(s), that call for a case-specific and "tailor made" approach to agri- 
environmental target setting. In this work it is suggested that the baseline situation should be modelled according to an integrated framework accounting for dynamic changes. In this respect we minimize the risk of false positives and false negatives. To this end we advocate a procedure that uses a dynamic, mass-balance water quality model to help explain the input (deposition) - output relationship and integrates science and socio-economic models to protect policy design from committing false positives or false negatives (Skuras et al., 2014).

Figure 2 depicts this approach in a sequence of policy design steps supported by science and social science methods and models. Once the non-compliance issue is recognized and defined (step 1) with the support of existing data and socio-economic public participation models, an integrated model of nutrient and sediment transportation within the catchment is proposed to be constructed (step 2). This step is supported by scientific models of nutrients and/or sediment transport that calibrate a baseline situation based on flow and hydrochemistry conditions of the catchment depicted by meteorological, soil-geological, flow, land use and water quality data. In step three, decision makers will have the capacity to avoid false negatives and false positives. False positives are usually generated by failing to take into account the whole range of sources contributing nutrients to the watershed and overestimate the contribution and impact of agriculture. In this context, adopting a policy to control nitrogen deposition from agriculture will not have an effect. Potentially, false positives may be generated by situations in which high nutrient deposition fails to show up in water nutrient concentrations for various reason including geology, e.g., extensive carstic phenomena that redirect nutrient rich water to neighbouring watersheds or to 
underground water reservoirs, soil conditions that favour high denitrification, deposition at river banks, etc.

In steps 4 and 5, mitigation measures are proposed and their effect is examined according to the calibrated baseline model. This will allow the examination of the simulated effectiveness of the mitigation measures and hence, the prevention of false positives, by adopting measures that will not be effective or the prevention of false negatives, by rejecting measures that will be effective (step 6). In step 7 the baseline condition and the mitigation measures are re-estimated and simulated against changing conditions including climate, land use and production. This will allow the prevention of false positives in the sense that a deposition-concentration situation that seems positive today may be most likely ameliorated in the near future due to changing conditions, without the need of mitigation measures and thus, adopting a programme would be less appropriate (step 8). The same step will allow the prevention of false negatives in the sense that a seemingly unrelated depositionconcentration situation today may be most likely aggravated in the near future due to changing conditions and adopting mitigation measures under an agri-environment programme would be appropriate.

\section{Case Study and Methods}

\subsection{The case study area of the Louros watershed}

The Louros water catchment $\left(926 \mathrm{~km}^{2}\right)$ is situated in the central-southern part of the Epirus (NUTS 2 region) Water District in Greece. The river rises in the mountains adjacent to the "Dodoni Oracle", one of the most important and famous oracles of ancient Greece. The main river flows for $72 \mathrm{~km}$, and its waters are derived from many 
spring and snow fed tributaries. The river forms a delta where it empties into the Amvrakikos Gulf, a site listed under the Ramsar Convention and the Natura 2000 network ${ }^{1}$. The river's delta includes freshwater marsh with the largest reedbeds in Greece, wet meadows and seasonally inundated land, lagoons, barrier spits, a major saltmarsh, and some of the most extensive tracts of riparian forest remaining in Greece. The Amvrakikos Gulf is very important for biodiversity and a unique biogeographical refuge in the migratory route between Europe and Africa. Located deep into the Mediterranean, well-connected to the Balkans and the European

222 mainland serves as a bridgehead for mutliple migration routes from and towards Africa with 182 bird species observed to breed, winter, or stage in the area. Of these special conservation measures ${ }^{2}$.

The river's annual discharge at its mouth is $95.13 \mathrm{~m}^{3} / \mathrm{s}$ and the density of its hydrographic network in the catchment is $0.69 \mathrm{~km} / \mathrm{km}^{2}$. Despite the operation of a relatively small (10.3 $\mathrm{MW}$ ) hydroelectric power plant, the river has continuous water flow due to the serious siltation of the dam. The upper part of the catchment is mountainous and semi-mountainous with the highest elevation at 1,976 m. The lower

231 part of the catchment is plain and Louros river, together with the adjacent Arachthos river, irrigates and drains the most significant plain, in terms of agricultural production,

233 of Western Greece. The catchment receives relatively large volumes of convective precipitation, and rainfall is high for Mediterranean conditions. The average annual

\footnotetext{
${ }^{1}$ The site's description and map under the Ramsar Convention can be found at: https://rsis.ramsar.org/ris/61 and under the Natura 2000 network at: http://natura2000.eea.europa.eu/ ${ }^{2}$ Last amendment of Annex I of Directive 79/409/EEC is found in Directive 2009/147/EC, Official Journal, L20/7 of 26.1.2010.
} 
precipitation ranges from $800 \mathrm{~mm}$ per year in the lowlands up to $1300 \mathrm{~mm}$ per year in the mountainous areas. Today, Louros provides drinking and industrial water to the three largest urban areas of the catchment and many smaller towns. Farming, tourism, stock raising, aquaculture at the uplands and fish farming at the estuaries are the most important economic activities directly or indirectly dependent on the quality and quantity of Louros' water.

Chemical analyses undertaken in several monitoring points indicate high conductivity and concentrations of pollutants mostly in the estuary where drainage channels return drained irrigation water. The river has been highlighted as vulnerable for eutrophication, and two published studies have classified the water quality as "fair" or "poor to fair" (Ovezikoglou et al., 2003; Kotti et al., 2005). However, nutrient concentrations are recorded in relatively low levels in the published studies (average nitrate $<1 \mathrm{mg}-\mathrm{N} / \mathrm{L}$, average phosphate $<15 \mu \mathrm{g}-\mathrm{P} / \mathrm{L}$ ). Maize, medic (clove) and cotton are the most widely spread irrigated arable cultivations with considerable fertilization, while wheat is mostly rain-fed with minimum fertilization. Citrus fruits, mainly orange and mandarins and to a less extent lemon trees and kiwi fruits are the most important irrigated perennial cultivation while olive groves are mostly rain fed with minimum or no use of fertilizer.

Extensive consultation with the scientific community and stakeholders concluded that the almost 10,000 ha of intensively cultivated land within the watershed (3,300 ha of maize; 4,000 ha of medic; 340 ha of cotton; and 2,100 ha of citrus fruit) contribute an average annual of about 1,780 tons of nitrogen and 1,160 tons of phosphorous in terms of deposited active substance. Local scientists and stakeholders were presented with average national estimates of fertilization per 
cultivation and per hectare. Then, they were asked to adapt them (increase or decrease) for the local corresponding cultivations and provide the reasons why they suggested adaptations. For example, maize cultivations, depending on the site and soil properties, accept during starter band fertilization an average of 1,000 kg of fertiliser with a NPK ratio of 16-20-0 were applied per hectare corresponding to $160 \mathrm{Kg}$ of N, or $1,000 \mathrm{Kg}$ of $18-12-8$ fertiliser corresponding to $180 \mathrm{Kg}$ of $\mathrm{N}$ per hectare. During surface fertilization the same plots accept usually 300 to $350 \mathrm{Kg}$ of $25-0-0$ fertiliser per hectare corresponding to 75 to $90 \mathrm{Kg}$ of $\mathrm{N}$. The corresponding phosphorous fertilization is about $120-200 \mathrm{Kg}$ per hectare depending on soil needs by using either $18-12-18$ or 16 20-0 fertiliser during starter band fertilization. Application of phosphorous during surface fertilization is rare in the case of maize.

Water chemical analyses carried out by the Greek Ministry of Rural concentration of nutrients (nitrates, ammonium and total phosphorous) was relatively high at least during autumn and early winter. Following this rather weak evidence, in

2742006 MRDF established the plains of the Louros catchment and part of the adjacent Arachthos catchment, as a Nitrification Vulnerable Zone (NVZ) under the Nitrates

276 Directive. The plan that, as yet, has not been implemented due to Greece's financial 277 crisis and consequent budgetary constraints, allows compensation for farmers of the 278 aforementioned cultivations if they comply with measures or combination of 279 measures including the set aside of land, maximum allowable fertilization levels and 280 irrigation per cultivation. 


\subsection{Baseline Modelling}

In this work, the INCA-N and INCA-P integrated catchment models were used to simulate the distribution of nitrogen and phosphorous correspondingly in the aquatic and terrestrial environment. The models can simulate the annual and seasonal variations in the stream-water concentrations of nitrate (NO3), ammonium (NH4), total phosphorous (TP) and dissolved phosphorous (DP) (Wade et al, 2002a, 2002b). The models take account of anthropogenic nutrient inputs in the form of fertiliser or sewage discharges on top of natural nutrient inputs through atmospheric deposition, vegetation and mineralisation (and subsequent nitrification). Figure 3 shows the flowchart of calibrating the INCA-N baseline model for the Louros watershed and of using the model for simulating the effects of mitigation measures and the effects of future climate and land use changes. A similar flowchart holds when applying the INCA-P model. The quality and quantity of data Inputs is the most crucial stage in calibrating the baseline models (Figure 3). The Louros catchment was divided into 16 smaller reaches (or sub-catchments), according to where observations of chemistry or flow are available, a procedure that is considered standard for semi-distributed models (Whitehead et al., 1998). The groundwater recharge area of the Louros is considerably larger than the topographic catchment due to the extensive karstic formations. For each of the 16 sub-catchments, daily temperature and precipitation data were estimated from the three meteorological stations situated in or around the catchment, weighted using Theissen polygons. Detailed land cover for six major classes was provided by CORINE.

For each crop, scientific sources and communication with expert agronomist in the area were utilised to calculate average deposition rates for each nutrient and 
their approximate time of application. In addition, information was collected for the

irrigation water needs of each crop. These calculations were presented to stakeholders during locally organized workshops and were fine tuned for various cultivation practices, micro-environments and multinutrient fertilisers. Nutrients applied through manure were estimated from annual statistical records assuming an average output per type of grazing animal. Hog farming depositions were also calculated as point source pollution directed to river reach. non-arable land use classes. This was assumed to equal $4 \mathrm{~kg}-\mathrm{N} /($ ha $\cdot y e a r)$ for shrub land, and $10 \mathrm{~kg}-\mathrm{N} /($ ha.year) for forests. For phosphorus, the respective quantities were at a rate of $1 \mathrm{~kg}-\mathrm{N} /$ (ha-year) for shrubland and of $2 \mathrm{~kg}-\mathrm{P} /$ (ha.year) for forests. Finally, annual atmospheric values of dry and wet deposition of nitrate and ammonium were calculated per European Monitoring and Evalution Programme (EMEP) grid square (Cooperative Programme for Monitoring and Evaluation of the Long-range Transmission of Air Pollutants in Europe). The Louros catchment is covered by three different EMEP squares. Wet deposition was separately calculated for forested and non-forested land cover. A 50-50 split between nitrate and ammonium added as solid $\mathrm{P}$, and $30 \%$ as liquid $\mathrm{P}$.

To model the hydrology, the hydrological model PERSiST (Precipitation, Evapotranspiration and Runoff Simulator for Solute Transport) was used (Futter et al., 2013) to generate hydrological input data (Hydrological effective rainfall and Soil moisture deficit) needed to drive the chemical INCA models. The model was set up with the aforementioned six land cover and three different soil boxes, i.e., one quick 
box, one soil box and one groundwater box. Each box is characterized by nine different parameters, which are specific for each land class. There are nine additional land cover specific parameters, related to properties such as snow melt, evapotranspiration and base flow index. PERSiST was calibrated against the observed flow for the period Jan 2001 - Sep 2012. The INCA-N parameters calibrated included soil denitrification, soil nitrification, soil mineralisation, plant $\mathrm{NO}_{3}$ uptake, plant $\mathrm{NH}_{4}$ uptake, in-stream nitrification, in-stream denitrification, initial groundwater nitrate and initial groundwater ammonium. The size of the point source (effluent concentration of ammonium) was also calibrated, the hydrological parameters of groundwater residence time was adjusted to improve the fit for base-flow conditions, and the drought runoff fraction was adjusted to keep more nitrogen in the soil during the dry summer months. The INCA-P parameters calibrated included soil phosphorus terms (Freundlich isotherm, weathering factor, sorption coefficient and equilibrium phosphorus concentrations), plant uptake, process rates response to temperature, immobilisation, initial labile and inactive soil $\mathrm{P}$, reach ecology parameters for macrophytes and epiphytes, and groundwater phosphorus terms. Both models, INCA$\mathrm{N}$ and INCA-P were calibrated against nutrient concentration data from monitoring stations operated by the Ministry of Environment and Energy with reasonably good overall results and goodness of fit measures.

\subsection{Simulating mitigation measures and future changes}

In this section we detail the processes for simulating the effects of mitigation measures and the effects of future climate and land use changes on the baseline. In Figure 3 , once the baseline simulation has been calibrated, we decide whether 
mitigation measures are needed. If mitigation measures are introduced, their effect on reducing nutrients loads is simulated on the lower left part of the Figure 3 . This is an iterative process up until compliance is achieved, because the proposed mitigation measures may not be effective. Once we end up with a set of effective mitigation measures, or if no mitigation measures are needed, we examine whether the preferred mitigation measures remain effective under future climate and land use scenarios. This simulation exercise is shown on the lower tight part of Figure 3. At the end of this process the decision maker will have enough and strong evidence for the effectiveness of the proposed mitigation measures and their resilience to future climate and land use changes and adequate information to establish a coherent monitoring system. If more than one alternative mitigation measures comply with the thresholds and are resilient to future climate and land use changes, then the decision maker will be able to choose the most cost-effective.

In order to simulate the adoption of an agro-environmental programme we considered mitigation measures that have been introduced in other NVZs during the implementation of the 2007-2013 Rural Development Programme in Greece. For annual cultivations the proposed agro-environmental scheme (Mitigation 1) includes a composite scheme with $5 \%$ of the total land occupied by non-cultivated margins, $20 \%$ of the land under rotation with nitrogen fixing legumes, $20 \%$ of the land under half of the standard fertilization scheme, and $25 \%$ reduction in the deposition of fertilizers to the rest $55 \%$ of the land. This scheme achieves $51.25 \%$ reduction in fertilization deposition in relation to the baseline. For each one of the major annual cultivations (maize, cotton and medic), the actual deposited quantities of fertilizers are calculated and subtracted from the total deposition in each sub-catchment. 
Furthermore, adaptations are made to take account of uncultivated margins by reducing the leaching coefficient. The proportional reduction in irrigation water is also simulated. For perennial plantations of citrus fruit only a $25 \%$ reduction in deposited fertilizers is considered. The same measure was simulated with increased reductions to $30 \%$ (Mitigation 2). In this scheme, the cultivated land is distributed to $5 \%$ uncultivated margins, $25 \%$ under nitrogen fixing legumes, $25 \%$ with half the fertilization and the rest $45 \%$ of the land with a $30 \%$ reduction in fertilization and irrigation. For citrus fruit plantations a $30 \%$ reduction in fertilization is envisaged.

For each cultivation, the mitigation measure cost was calculated based on Standard Gross Margins (SGMs) provided for the region of Epirus by Eurostat's FADN, the Farm Accountancy Data Network. The standard Gross Margin (SGM) of acultivation is defined as the value of output from one hectare less the cost of variable inputs required to produce that output. We assume that agro-environmental policies induce only temporary changes to farm practices and thus, the constant cost of fixed assets such as capital, land, and buildings is not affected and should not enter the cost calculations.

Meteorological data from three different climate models were used to define the meteorological time series for the 2031-2060 scenario-period, namely the KNMIRACMO2-ECHAM5 (abbreviated thereafter as KNMI), the SMHIRCA-BCM (abbreviated thereafter as SMHI) and the HadRM3-HadCM3Q model (abbreviated thereafter as Hadley) (Christensen et al., 2009). Observed meteorological time series were adjusted by the average difference between the control and scenario periods for each month and for each of the three climate models, as more sophisticated methods (downscaling with a power function) resulted to very unrealistic precipitation 
amounts, especially for summer months. The predicted relative changes in precipitation did not differ substantially among the three climate models, with the least change predicted by the KNMI model (-12 \%) followed by the SMHI model (-14\%) and the Hadley model (-16 \%). The seasonal patterns in precipitation change were seemingly random, except for the month of July for which all three climate models predict a large decrease in precipitation (55-65\%). As concerns temperature, the three climate models were more different, with the SMHI model predicting the smallest increase $\left(+1^{\circ} \mathrm{C}\right.$ on average), the Hadley model predicting the largest increase $\left(+2.2^{\circ} \mathrm{C}\right)$, and the KMNI predicting an intermediate decrease $\left(+1.8^{\circ} \mathrm{C}\right)$. Seasonal patterns are also more pronounced, with a smaller increase in winter temperatures and a larger increase in summer temperatures. The modelled climate change effects have an impact on the hydrology of the area. For example, in one of the central and most important reaches of the river, the simulated flow for the control period 1981-2010 was $16.6 \mathrm{~m}^{3} / \mathrm{s}$ and decreased by $14.9 \%, 18.3 \%$ and $27.7 \%$ under the $\mathrm{KNMI}$ the SMHI and the Hadley models respectively. There is an even greater effect on the annual minimum flow. For the same reach, the average annual minimum flow for the control period was $8.1 \mathrm{~m}^{3} / \mathrm{s}$ and is decreased by $20.6 \%, 5.5 \%$ and $29.3 \%$ for the KNMI the SMHI and the Hadley models respectively.

Climate change will also induce long term land-use and plant productivity changes depending on the IPCC storyline (Nakicenovic et al., 2010). In general, the IPCC storylines refer to the ' $A$ '-scenarios representing a market-oriented future and the ' $\mathrm{B}$ '-scenarios representing a more environmental-oriented future. Furthermore, the ' 1 '-scenarios represent a future globalised world, whereas the '2'-scenarios represent a world with stronger national or local regulations. These storylines are 
combined to produce various scenarios, e.g., $A 1, B 1, A 2, B 2$, and their variants. These scenarios have direct impact on forecasted $\mathrm{CO}_{2}$ concentrations. In 2009, the Bank of Greece set up the "Climate Change Impacts Study Committee" with the mandate to draft a report presenting the foreseen environmental, economic and social impacts of climate change and estimating the cost of these changes for the Greek economy as well as the cost of the proposed adjustment measures (Zerefos et al., 2011). In this study, climate change impacts on agriculture have been measured for each of 11

Greek climate zones. The researchers used the AquaCrop (version 3.1, 2010) model developed by the FAO (Doorenbos and Kassam, 1979) for modelling crop production in relation to water (especially for rain fed cultivations) and an estimated higher production response under increased concentrations of $\mathrm{CO}_{2}$ and less production under the risk of severe climate phenomena and diseases. area to produce alternative broad land use and fertilization changes. For the Louros watershed, the highest negative change is projected for wheat (almost $-10 \%$ of land area planted) and the highest positive change is projected for cotton, vineyards and olive groves (almost $+10 \%$ ). The fertilization for all other cultivations either remains 444 unchanged or is projected with minor (less than $5 \%$ ) negative or positive changes. The aforementioned IPCC storylines are combined with climate change model forecasts to 446 produce alternative combinations of long term climate and land use changes. In the case of the Louros watershed, the scenario with the least impacts, called thereafter 448 the "best" future scenario, is the KNMI model combined with the B1 storyline and the scenario with the most severe impacts, called thereafter the "worse" future scenario comes from the Hadley model combined with the A2 storyline. 

reforms. The CAP, since 2005, has gradually moved away from coupled payments towards more decoupled payments. Greece adopted the so called historical model

454

455 that calculated decoupled payments based on historical records of production and subsidies. For many products, decoupled subsidies are granted almost unconditionally with the only obligation being for the farmers to take care of the good ecological status of the land. For cotton, $65 \%$ of the subsidy is decoupled and $35 \%$ depends on delivering a minimum amount of cotton. This has affected both the area used for cotton and the amount of deposited nutrients. The land under cotton has decreased dramatically especially by farmers who choose to take the decoupled part and switch cultivation or leave the land uncultivated. The farmers targeting both the decoupled and the coupled parts of the cotton subsidy do not aim to maximize production but to minimize costs, including cost for fertilization, because the minimum production allowing the farmer to qualify for the coupled part of the subsidy is very low and can be attained with minimum inputs. In the period following decoupling (2005-2009) the area cultivated by cotton was reduced by almost $40 \%$ and the area under wheat by almost 30\%. Taking into account the Commission's decision to continue this trend for further decoupling and the new binding "Greening" rules for 2014-2020, we assumed that an amount of marginally fertile land cultivated by cotton and maize will be withdrawn and a reduction of fertilization will take place within a wider farm survival strategy to reduce operating costs.

After extensive consultation with the scientific community and local stakeholders, it was decided to model land use change due to the changing agricultural policy and markets for agricultural products as a $25 \%$ set aside for capturing those 
farmers who will stop farming with the decoupled part of the subsidy and a $25 \%$ reduction in the use of fertilizers for those farmers who will continue cultivation, aiming to the coupled part of the subsidy. This land use scenario was translated to reduced nutrient deposition per cultivation and sub-catchment because certain cultivations such as cotton are highly localized within the watershed. Following the suggestions from the projections of local stakeholders, we escalated the same land use projection to $30 \%$ reduction in land cultivated and fertilizer used and run both simulations.

\section{Results}

\subsection{The occurrence of a False Positive}

Taking into account only the supply of nutrients, and especially those from agricultural activity, it is estimated that the watershed accepts an amount of 2,594 tonnes of active $\mathrm{N}$ substances and 1,578 tonnes of active TP per annum from which agriculture is responsible for almost 1,780 tonnes of $N$ and 1,163 tonnes of $P$ for the major cultivations within the watershed. These amounts of active fertilizer substance alone are enough to trigger public concerns over agricultural activity in relation to the high nature value of the lagoon and its importance for European biodiversity, despite the fact that monitoring data were sparse and showed at most moderate nutrient concentrations and few signs of eutrophication. The simulated average and monthly concentrations for nitrates, ammonium and Total Phosphorous (TP) are shown in Figure 4.

Simulated nitrate concentrations near the estuary range between 0.8-1.0 mg $\mathrm{N} / \mathrm{L}$ with an average at $0.9 \mathrm{mg} \mathrm{N} / \mathrm{L}$, while ammonium concentrations range from $0.04-$ 

$0.13 \mathrm{mg} \mathrm{N} / \mathrm{L}$ with an average of $0.08 \mathrm{mg} \mathrm{N} / \mathrm{L}$. TP concentration ranges from 0.02-0.11 $\mathrm{mg} \mathrm{TP} / \mathrm{L}$ with an average of $0.05 \mathrm{mg} \mathrm{TP} / \mathrm{L}$ and SRP concentration from 0.01-0.11. $\mathrm{mg}$ SRP/L with an average of $0.04 \mathrm{mg} \mathrm{SRP/L}$. Skoulikidis et al (2006) have proposed a Nutrient Classification System (NCS) for small/medium sized rivers in Greece based on annual average concentrations from 36 sites throughout Greece. According to this system, the river is classified as of moderate quality in relation to nitrates $(0.6-1.3 \mathrm{mg}$ $\mathrm{N} / \mathrm{L})$ and ammonium (0.06-0.20 mg N/L) and of high quality in relation to TP (0.17-0.22 mg TP/L). Under other classifications, e.g., the nutrient quality classes in French and Italian rivers (Skoulikidis et al., 2006), the Louros river would be placed between a "Good" and "Moderate" class. At the same river and sub-catchments, Macrophyte data (taxon name and abundance class) were collected and the IBR (Indice Biologique Macrophytique en Rivière - Macrophyte Biological Index for Rivers) was calculated by Manolaki et al (2011) according to the methodology proposed by Haury et al. (2006). Of the 17 sites they studied, eight are characterized as having "High" ecological status, three as "Good", four as "Moderate" and two as "Poor". The best predictors for the decrease in IBMR values were salinity and water temperature, while SRP was also found to be correlated with IBMR but able to explain only $47 \%$ of the variability in IBMR values. The classification of the river's estuaries based on the aforementioned simulated results was re-confirmed in 2013 by the Management Plan drawn for Epirus' water resources.

Thus, assuming that there is a direct positive relationship between agricultural activity and nutrient concentration would be a false positive, i.e., assuming a direct relation that does not exist. This further supported by the fact that nitrate concentrations tend to be highest in the upper reaches, which are not affected by agriculture, while 
the poor ecological status for macrophytes can obviously not be attributed to nutrient concentrations. There are several alternative explanations of why nutrient deposition rates do not really contribute to high nutrient concentrations downstream. As local stakeholders argue, due to cost minimization strategies and the rising price of fertilizers and energy, farmers take very good care of the time of fertilizer application, of the appropriate amount of fertilizer and of irrigation. This may contribute to a more balanced nutrient deposition and nutrient uptake by plants leaving less residual nutrients on the soil. In the framework of cost minimization there is also reduced and more precisely applied irrigation for reducing the cost of energy. Thus, higher uptake by plants also may be supported by longer water residence time in the soil brought about by more modern irrigation schemes (drop irrigation) that are gradually replacing sprinklers. This practice also reduces leaching and nutrient transportation.

Finally, there are well documented physical and biological processes that may contribute to lower nitrogen levels despite higher deposition rates. Denitrification and nitrogen immobilization in excess of mineralization, at least temporarily when temperature is high and the concentration of soil C is high (Saggar et al., 2013). High spring and summer temperatures enhance aerobic respiration and denitrification while aerobic respiration further enhances denitrification by consuming oxygen, resulting in strong sensitivity of denitrification to temperature though substrate type and soil moisture may limit microbial processing (Butterbach-Bahl et al., 2013; Luo et al., 2013). Finally, sediment and thus nutrient transportation has been reduced in the area due to the extensive drainage and river bank stabilization works that have been undertaken throughout the watershed in the last 30 years. 


\subsection{Agri-environmental Measures and Future Changes}

The simulated effects of agri-environmental measures, climate change, land use change and their combinations on nutrient concentration at the reach nearest to the estuaries of Louros river are presented for the simulated concentrations of nitrate, ammonium, SRP and TP in Table 2. If the mitigation measures described in section 3 of this work are adopted, the simulated reduction in average nitrate and ammonium concentrations is not significant. Quantitatively, exactly the same changes can be effected by short-term land use changes induced by the CAP without any mitigation measure. Furthermore, as concerns long-term climate change impacts, even the effect of the worse scenario does not show any important impact on nitrates and ammonium concentrations. The imperceptible modelled net change in nitrate concentrations for the climate scenarios is due to the fact that the amount of nitrogen leaching from the soils decrease by approximately the same rates as the runoff. At the same time, the average discharge decreases by between 15 and $28 \%$, the amount of nitrogen leaching from the soils decreases by $15 \%$ (KNMI and SMHI models) to $25 \%$ (Hadley). The amount of nitrogen transported to the estuaries is however substantially reduced, by $16.3 \%$ for the $\mathrm{KNMI}$ climate, $17.0 \%$ for the SMHI climate, and by $26.5 \%$ for the Hadley climate. The main reason for the simulated decline in nitrate leaching is that longer water residence time in the soil and stream and less runoff meant that more of the nutrients were available for plant uptake which balances the additional fertiliser load under increased $\mathrm{CO}_{2}$ concentrations. Furthermore, due to lower atmospheric deposition, the external loads were around $5 \%$ lower for the climate change scenarios. 

significant on phosphorous than on nitrates and ammonium. Mitigation measures reduce SRP from 27.3\% (Mitigation1) to 30.1\% (Mitigation 2) and TP from $24.3 \%$ (Mitigation 1) to $27.2 \%$ (Mitigation 2). This reduction can, for sure, classify the river to

574 the "Good" status as concerns phosphorous. The same results are achieved by the scenario of short-term land use change induced by CAP. As concerns the sole effect of 576 climate change, no significant changes are observed. The simulated response of 577 phosphorus concentrations to climate change is mainly due to a combination of 578 decreased leaching due to higher removal rates from the soil brought by longer soil 579 water residence times, and less dilution due to reductions in flow. The amount of SRP 580 leaching from the soil decreased by $16.9 \%$ (SMHI), 18.7 \% (KNMI) and 35.6 (Hadley).

581 The amount of SRP transported to the estuary is reduced by $31.1 \%$ (SMHI), $34.4 \%$ 582 (KNMI) and $46.6 \%$ (Hadley). Although results from the three climate models differ 583 somewhat, the tendency is that the increase of phosphorus concentrations will be 584 more pronounced during summer months, whereas they will remain unchanged or 585 even decrease during the winter months. The month of July stands as an exception to 586 this pattern, for which phosphorus concentrations remained nearly unchanged. This 587 may be attributed to the forecasted low precipitation, which results in less phosphorus 588 leaching from the soil. From the aforementioned discussion it is clear that, if mitigation measures are 590 adopted in order to upgrade the status of the river's water quality to "Good", at least 591 as concerns nitrates and ammonium, their effect is weaker than the effect that can be 592 achieved by the short-term land use changes observed and envisaged under the 593 reformed CAP. Thus, accepting that mitigation measures will be able to upgrade the 
river's water quality as concerns nitrates to "Good" and comply with WFD's requirements, will be yet another false positive decision in the design of agrienvironmental policy. A false negative may emerge if decision makers fail to recognize the effect of short-term land use changes at least on phosphorous. Climate change does not seem to exert an important positive (best scenario) or negative (worse scenario) effect. In all scenarios, TP is reduced, even slightly. Recent evidence shows that phosphorus can determine river phytoplankton growth irrespective of the nitrogen concentration (Wang and Wang, 2009) and the physical conditions of light, water temperature and residence time are important in lowland river catchments.

\subsection{The Cost of a False Positive}

For each one of the four major cultivations in the watershed the cost of the mitigation measures was estimated. In order to proceed in our calculations we carried out two focus groups with stakeholders and elite interviews with agronomists in the area. Farmers' income from the different cultivations was estimated from the Standard Gross Margins derived by the FADN database for the region of Epirus where the Louros watershed is situated. From the FADN database we also calculated initial estimates of the cost of fertilization, and the cost of cultivating lentils, as well as the SGM of the lentil for fodder. Elite interviews with agronomists were utilised to estimate the loss in production due to reduced fertilization and irrigation. Consequently, stakeholders were presented with the initial estimates during a focus group with the aim to discuss and adapt initial estimates of the exact effects of reduced fertilization and irrigation on production and on farmer's income. In the context of this focus group, the transaction cost for submitting an environmental plan 
and subscribe to an agri-environmental programme were also estimated. The cost of the mitigation measures for each one of the four major cultivations was estimated as income forgone from reduced production plus transaction costs minus cost avoided from reduced fertilization and irrigation and fodder production. For citrus fruit plantations only income forgone was estimated, as there is no way to have land under set-aside.

The average cost estimates for abating nitrates and TP for the different cultivations in the area and the watershed as a whole, should the Mitigation 1 scheme be adopted by all farmers located within the hydrological boundaries of the watershed, is presented in Table 3. The upper part of Table 3 provides average cost estimates for fertilizer reduction per hectare (ha) and kilogram $(\mathrm{kg})$ of active substance for the four major cultivations and the watershed as a whole. The cost per hectare varies significantly from $437.2 €$ /ha for the less profitable cultivation of medic to 657.2 $€ /$ ha for the most profitable cultivation of cotton. The cost of abating one $\mathrm{Kg}$ of pure nitrogen ranges from $4.5 € / \mathrm{kg}$ for corn to $12.5 € / \mathrm{kg}$ for medic. For phosphorous, the cost of abatement per $\mathrm{Kg}$ is much higher than for nitrogen ranging from a high of almost $54 € \mathrm{~kg}$ for citrus fruit cultivation to a low of $5.4 € / \mathrm{kg}$ for corn.

These estimates can be compared with past estimates of abatement costs for seven EU Member States carried out in the framework of a study estimating the ex post costs of implementing the Nitrates Directive in Europe (Kuik, 2006). In this study, cost estimates at 2004 prices range from a high $236 € /$ ha in the Netherlands to a low of $6 € /$ ha in the UK, which, however, refer to livestock and grasslands respectively. As concerns the cost per $\mathrm{Kg}$ this range from a low $0.4 € / \mathrm{kg}$ for Croatia, then not a member State of the EU, to a high of $3.5 € / \mathrm{kg}$ for the Netherlands. Taking into account that 
these estimates were derived with the Nitrates Directive in focus, they refer to grasslands and livestock which are not as intense activities as, for example, cotton. They also target a nitrogen concentration of $50 \mathrm{mg} / \mathrm{l}$ set up by the Nitrates Directive for sub-surface waters. In our study, the nutrient loads are already low and thus the marginal abatement cost is at its steeply rising part. An indirect way to measure abatement cost is through prohibitive standards, penalties and/or taxes. In the Netherlands, between 1998 and 2005, penalty-free thresholds were gradually reduced - for example, for nitrogen from $300 \mathrm{~kg} / \mathrm{ha}$ to $140 \mathrm{~kg} / \mathrm{ha}$ for grassland farms (Goffe, 2013). Penalties, in the Netherlands were fixed at $€ 0.68 / \mathrm{kg}$ for nitrogen and $€ 2.60-€ 10.40 / \mathrm{kg}$ for phosphorous in 1998 , and were increased to $€ 2.53-€ 5.07 / \mathrm{kg}$ and $€ 20.60 / \mathrm{kg}$ respectively (Goffe, 2013) while levy taxes in 2003 were set to $2.3 € / \mathrm{Kg}$ for nitrogen and $9.1 € /$ Kg for phosphate (Söderholm and Christiernsson, 2008) which compare with the results of our study.

The focus of this study, however, is to reveal the high abatement cost when this is measured in terms of reduced nutrient concentration downstream. The cost estimate for nitrates is unreal at the unprecedented levels of just over 300 thousand euro per reduced microgram per litre $€ /[(\mu \mathrm{g} / \mathrm{l})]$. For phosphorous this is at 412,398 $€ /[(\mu \mathrm{g} / \mathrm{l})]$. So, a false positive decision to comply with WFD and attain a "Good" status as concerns nutrient loads would be obviously unacceptable by any taxpayer in Europe. Which are the reasons for this case? First, the nutrient status is already at "Moderate" to "Good", i.e., the nutrient concentration is already low compared to the $50 \mathrm{mg} / \mathrm{l}$ threshold of the Nitrates Directive. Thus, the marginal cost to attain an even lower level of concentration is extremely high. Second, at this level of concentration, the simulations showed that even the withdrawal of $30 \%$ of the cultivated land will 
not reduce nitrate concentration by more than $0.02 \mathrm{mg} / \mathrm{l}$ and TP concentration by 0.01 $\mathrm{mg} / \mathrm{l}$. These are negligible achievements at a highly disproportional cost.

To summarize the discussion so far, it can be argued that the abatement cost of agri-environmental programmes aiming to manage nutrient loads should be measured as a change in nutrient concentration and not at levels of abated fertilizer. In other words, the targets of such agri-environmental programmes and policies should be set at nutrient concentration levels and not at quantities of abated substance either in mineral fertilizer or in manure and slurry. This can be attained if, during the design of agri-environmental programmes, the status quo (baseline), the impacts of the mitigation measures and the impacts from likely future changes are simulated. Then, false positives and false negatives can be avoided, the costeffectiveness of mitigation measures can be assessed and an appropriate monitoring system can be set up.

\section{Conclusions}

The EU's agri-environmental policy is a response to the growing public concern over the environmental impacts of agriculture. As such, agri-environmental policy attempts to meet requirements from the WFD, the Nitrates Directive and the Habitats Directive, the cornerstone of environmental conservation in Europe. Agrienvironmental policy has grown to a tremendous budget (€36.6 billion spent in the 2007-2013 programming period across the EU) and power by affecting almost a quarter of the EU's utilized agricultural area. This work concerned only with programmes managing nutrient loads in freshwaters and not with other forms of agrienvironmental programmes. Results showed that, under public pressure and 
seemingly high rates of mineral fertilization, decision makers may falsely adopt an agri-environmental programme that may be both, ineffective in reducing nutrient loads and cost inefficient. Furthermore, they fail to take account of future changes that may inactivate the proposed mitigation measures, aggravate or reverse the baseline situation.

The present work suggests that the design of such agri-environment programmes should evolve to a thoroughly designed, interdisciplinary exercise integrating science and social-science models in a step-wise procedure. This process will ensure decision makers with the highest possible information from scientific sources and models and from local knowledge. This information can be used by appropriate simulation models to calibrate the baseline situation. Once an appropriately calibrated model is derived, further scenarios simulating policy, land use and climate changes can be simulated. Based on these results the effectiveness and cost efficiency of the proposed actions and of envisaged changes can be assessed. As a result, decision makers will be able to grasp an ex-ante evaluation of the current situation and of the proposed mitigation actions, if needed. This will allow decision makers to monitor the current situation and respond by adopting new measures or adapting existing ones to the changing physical, social and policy environment.

Under this proposal, the cost of the design phase of an agri-environmental programme will increase. But, in view of the high cost of mitigation measures, such an increase in the design stage of the agri-environmental policy should be considered as an insurance against the commitment of very expensive false positive and false negative decisions. Finally, in this work it is proposed that the targets of agrienvironmental policy and consequently, the measurement of abatement cost should 
be done in terms of nutrient concentrations and loads in water and not in terms of

715 physical quantities of abated substance in the field. This will provide the cost efficiency

716 exercise with a wider perspective as concerns the sources of nutrients and abiotic,

717 biotic and anthropogenic activities that contribute the nutrient loads. In turn, this will

718 force agricultural policy decision makers to coordinate their actions with other

719 environmental policy makers for achieving maximum results and avoiding internal

720 contradictions.

721

722 Acknowledgments

723 This work was carried out as part of the REFRESH FP7 Project: Adaptive Strategies to

724 Mitigate the Impacts of Climate Change on European Freshwater Ecosystems, funded

725 by EU Seventh Framework Program (Grant Agreement

726 244121): www.refresh.ucl.ac.uk. The authors would like to thank two anonymous

727 referees of this journal for their constructive comments, and the associate editor

728 professor Simon Pollard for his efforts and support. 


\section{References}

Barbayiannis, N., Panayotopoulos, K., Psaltopoulos, D. and Skuras, D. 2011. The influence of policy on soil conservation: A case study from Greece. Land Degradation and Development 22(1), 47-57. DOI: 10.1002/ldr.1053

Batáry, P., V. Dicks, L., Kleijn, D., Sutherland, W. 2015. The role of agri-environment schemes in conservation and environmental management. Conservation Biology, 29(4), 1006-1016. DOI: 10.1111/cobi.12536

Buckley, C., Wall, D.P., Moran, B., O’Neill, S., Murphy, P.N.C. 2016. Farm gate level nitrogen balance and use efficiency changes post implementation of the EU Nitrates Directive. Nutrient Cycling in Agroecosystems, 104(1), 1-13. DOI: 10.1007/s10705-015-9753-y

Butterbach-Bahl, K., Baggs, E. M., Dannenmann, M., Kiese, R. and ZechmeisterBoltenstern, S. 2013. Nitrous oxide emissions from soils: how well do we understand the processes and their controls? Philosophical Transactions of the Royal Society B-Biological Sciences, 368, 1-13. DOI: 10.1098/rstb.2013.0122

Christensen, J.H., Rummukainen, M., and Lenderink, G. 2009. Formulation of veryhigh-resolution climate model ensembles for Europe. Chapter 5 (pp.47-58), In Van der Linden, P. and J.F.B. Mitchell (eds), ENSEMBLES: Climate change and its impacts: Summary of research and results from ENSEMBLES project. Met Office Hadley Centre, FitzRoy Road, Exeter EX1 3PB, UK. 160 pp.

Doorenboos, J. and A.H. Kassam (1979), "Yield response to Water", Irrigation and Drainage Paper No. 33, FAO Rome Italy, 193 pp. 
European Economic Community. 1991. Council Directive of 12 December 1991 concerning the protection of waters against pollution caused by nitrates from agricultural sources. Official Journal of the European Communities, L 375, 1-8.

Fowler, D., Steadman, C. E., Stevenson, D., Coyle, M., Rees, R. M., Skiba, U. M., Sutton, M. A., Cape, J. N., Dore, A. J., Vieno, M., Simpson, D., Zaehle, S., Stocker, B. D., Rinaldi, M., Facchini, M. C., Flechard, C. R., Nemitz, E., Twigg, M., Erisman, J. W., Butterbach-Bahl, K. and Galloway, J. N. 2015. Effects of global change during the 21st century on the nitrogen cycle. Atmospheric Chemistry and Physics, 15, 13849-13893. DOI:10.5194/acp-15-13849-2015

Futter, M. N., Erlandsson, M. A., Butterfield, D., Whitehead, P. G., Oni, S. K., and Wade, A. J. (2013). PERSiST: the precipitation, evapotranspiration and runoff simulator for solute transport. Hydrol. Earth Syst. Sci. Discuss., 10, 8635-8681, DOI:10.5194/hessd-10-8635-2013.

Goffe, P. 2013. The Nitrates Directive, Incompatible with Livestock Farming?. Policy Paper No. 93, 30th May. Notre Europe - Jacques Delors Institute. Dowloable from:

$\underline{\text { www.institutdelors.eu/media/nitratesdirective-legoffe-ne-jdi-may13.pdf }}$

Hans J.M. Van Grinsven, H.J.M., Tiktaka, A., Rougoorb, C.W. 2016. Evaluation of the Dutch implementation of the nitrates directive, the water framework directive and the national emission ceilings directive. NJAS - Wageningen Journal of Life Sciences, 78, 69-84. DOI: 10.1016/j.njas.2016.03.010

Haury, J., Peltre, M. C., Tremolieres, M., Barbe, J., Thiebaut, G., Bernez, I., Daniel, H., Chatenel, P., Haan-Archipof, G., Muller, S., Dutartre, A., Laplace-Treyture, C., Cazaubon, A., and Lambert-Servien, E. 2006. A new method to assess water 
trophy and organic pollution-the Macrophyte Biological Index for Rivers (IBMR): its application to different types of river and pollution. Hydrobiologia, 570, 153-158. DOI: 10.1007/s10750-006-0175-3

Howarth, R., Swaney, D., Billen, G., Garnier, J., Hong, B. G., Humborg, C., Johnes, P., Morth, C. M. and Marino, R. 2012. Nitrogen fluxes from the landscape are controlled by net anthropogenic nitrogen inputs and by climate. Frontiers in Ecology and the Environment, 10, 37-43. DOI:10.1890/100178

Howden, N. J. K., Burt, T. P., Worrall, F., Whelan, M. J. and Bieroza, M. 2010. Nitrate concentrations and fluxes in the River Thames over 140 years (1868-2008): are increases irreversible? Hydrological Processes, 24, 2657-2662. DOI: 10.1002/hyp.7835

Jackson, B. M., Browne, C. A., Butler, A. P., Peach, D., Wade, A. J. and Wheater, H. S. 2008. Nitrate transport in Chalk catchments: monitoring, modelling and policy implications. Environmental Science \& Policy, 11, 125-135. DOI:10.1016/j.envsci.2007.10.006

Kleijn, D., Sutherland, W.J. 2003. How effective are European agri-environment schemes in conserving and promoting biodiversity? Journal of Applied Ecology, 40, 947-969. DOI: 10.1111/j.1365-2664.2003.00868.x

Kotti, M.E., Vlessidis, A.G., Thanasoulias, N.C., and Evmiridis, N.P. (2005). Assessment of river water quality in Northwestern Greece. Water Resources Management, 19(1), 77-94. DOI: 10.1007/s11269-005-0294-z

Kuik, O. 2006. Ex ante and ex post costs of implementing the Nitrates Directive: Case study in the framework of the project 'Ex post estimates of costs to business of EU environmental policies'. Commissioned by European Commission, DG 
800

801

802

803

804

805

806

807

808

809

810

811

812

813

814

815

816

817

818

819

820

821

822

Environment, Unit G.1 Sustainable Development and Economic Analysis. Framework contract No ENV.G.1/FRA/2004/0081. Downloable from: ec.europa.eu/environment/enveco/ex_post/pdf/nitrates.pdf

Luo, G. J., Kiese, R., Wolf, B. and Butterbach-Bahl, K. 2013. Effects of soil temperature and moisture on methane uptake and nitrous oxide emissions across three different ecosystem types. Biogeosciences, 10, 3205-3219. DOI:10.5194/bg10-3205-2013

Macdonald, G. K., Bennett, E. M., Potter, P. A. and Ramankutty, N. 2011. Agronomic phosphorus imbalances across the world's croplands. Proceedings of the National Academy of Sciences of the United States of America, 108, 30863091.DOI: 10.1073/pnas.1010808108

Manolaki, P., Tsakiri, E., and Papastergiadou, E. 2011. Inventory of aquatic and riparian flora of Acheron and Louros rivers, and Zirou Lake in Western Greece. Fresenius Environmental Bulletin, 20(4), 861-874.

Matzdorf, B., Lorenz, J. 2010. How cost-effective are result-oriented agrienvironmental measures?-An empirical analysis in Germany. Land Use Policy 27, 535-544. DOI:10.1016/j.landusepol.2009.07.011

Nakićenović, N., J. Alcamo, G. Davis, B. de Vries, J. Fenhann, S. Gaffin, K. Gregory, A. Grübler, T.Y. Jung, T. Kram, E.L. La Rovere, L. Michaelis, S. Mori, T. Morita, W. Pepper, H. Pitcher, L. Price, K. Raihi, A. Roehrl, H.-H. Rogner, A. Sankovski, M. Schlesinger, P. Shukla, S. Smith, R. Swart, S. van Rooijen, N. Victor and Z. Dadi (2010), "IPCC Special Report on Emissions Scenarios", Cambridge University Press, Cambridge, UK. 
Ovezikoglou, V., Ladakis, M., Dassenakis, M., \& Skoullos, M. (2003). Nitrogen, phosphorus and organic carbon in main rivers of the western Greece. Global NEST Journal, 5(3), 147-156.

Randall, N.P., Donnison, L.M., Lewis, P.J., James, K.L. 2015. How effective are on- farm mitigation measures for delivering an improved water environment? A systematic map. Environmental Evidence, 4:18. DOI: 10.1186/s13750-0150044-5

Saggar, S., Jha, N., Deslippe, J., Bolan, N.S., Luo, J., Giltrap, D.L., Kim, D.G., Zaman, M. and Tillman, R,W. 2013. Denitrification and $\mathrm{N}_{2} \mathrm{O}: \mathrm{N}_{2}$ production in temperate grasslands: processes, measurements, modelling and mitigating negative impacts. Science of the Total Environment, 465(1), 173-195. DOI: 10.1016/j.scitotenv.

Skoulikidis, N., Amaxidis, Y., Bertahas, I., Laschou, S. and Gritzalis, K. 2006. Analysis of factors driving stream water composition and synthesis of management tools-A case study on small/medium Greek catchments. Science of the Total Environment, 362, 205-241. DOI:10.1016/j.scitotenv.2005.05.018

Skuras, D., Wade, A., Psaltopoulos, D. Whitehead, P. Kontolaimou, A. and Erlandsson, M. 2014. An interdisciplinary modelling approach assessing the costeffectiveness of agri-environmental measures on reducing nutrient concentration to WFD thresholds under climate change: the case of the Louros catchment. Operational Research, 14(2), 205-224. DOI: 10.1007/s12351-0140158-5. 
Söderholm, P. and Christiernsson, A. 2008. Policy effectiveness and acceptance in the taxation of environmentally damaging chemical compounds. Environmental Science and Policy, 11. 240-252. DOI:10.1016/j.envsci.2007.10.003

Verhoeven, J. T. A., Arheimer, B., Yin, C. Q. and Hefting, M. M. 2006. Regional and global concerns over wetlands and water quality. Trends in Ecology \& Evolution, 21, 96-103. DOI: 10.1016/j.tree.2005.11.015

Wade, A.J., Durand, P., Beaujouan, V., Wessel, W.W., Raat, K.J., Whitehead, P.G., Butterfield, D., Rankinen, K. and Lepisto, A. 2002a. A nitrogen model for European catchments: INCA, new model structure and equations, Hydrology and Earth System Sciences, 6, 559-582. DOI:10.5194/hess-6-559-2002, 2002.

Wade, A. J., Whitehead, P. G. and Butterfield, D. 2002b. The Integrated Catchments model of Phosphorus dynamics (INCA-P), a new approach for multiple source assessment in heterogeneous river systems: model structure and equations, Hydrology and Earth Systems Sciences, 6, 583-606.

Wang, HJ. and Wang, HZ. 2009. Mitigation of lake eutrophication: Loosen nitrogen control and focus on phosphorus abatement. Progress in Natural Science, 19(10), 1445-1451. DOI:10.1016/j.pnsc.2009.03.009

Zerefos, C., Capros, P., Natsis, A. Papandreou, A., Sabethai, I and Yfantopoulos, I. (eds.) 2011. The environmental, economic and social impacts of climate change in Greece. Bank of Greece (in Greek). 


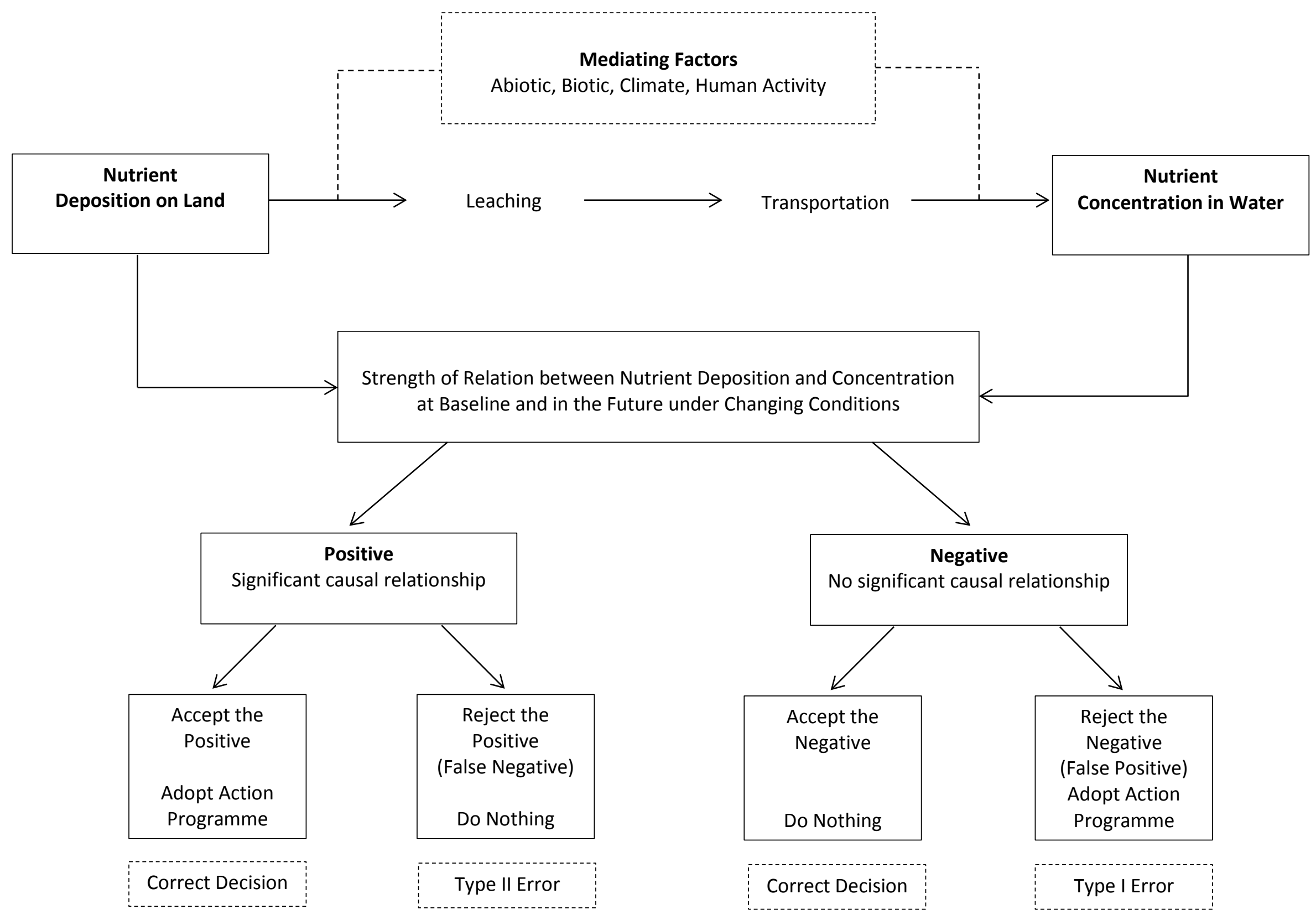


Figure 1. Sources of False Positive and Negative Errors in the design of agri-environmental measures. 


\section{A Decision Making Process for Rejecting False Positives and False Negatives}

in the Design and Implementation of Agri-environmental Policies

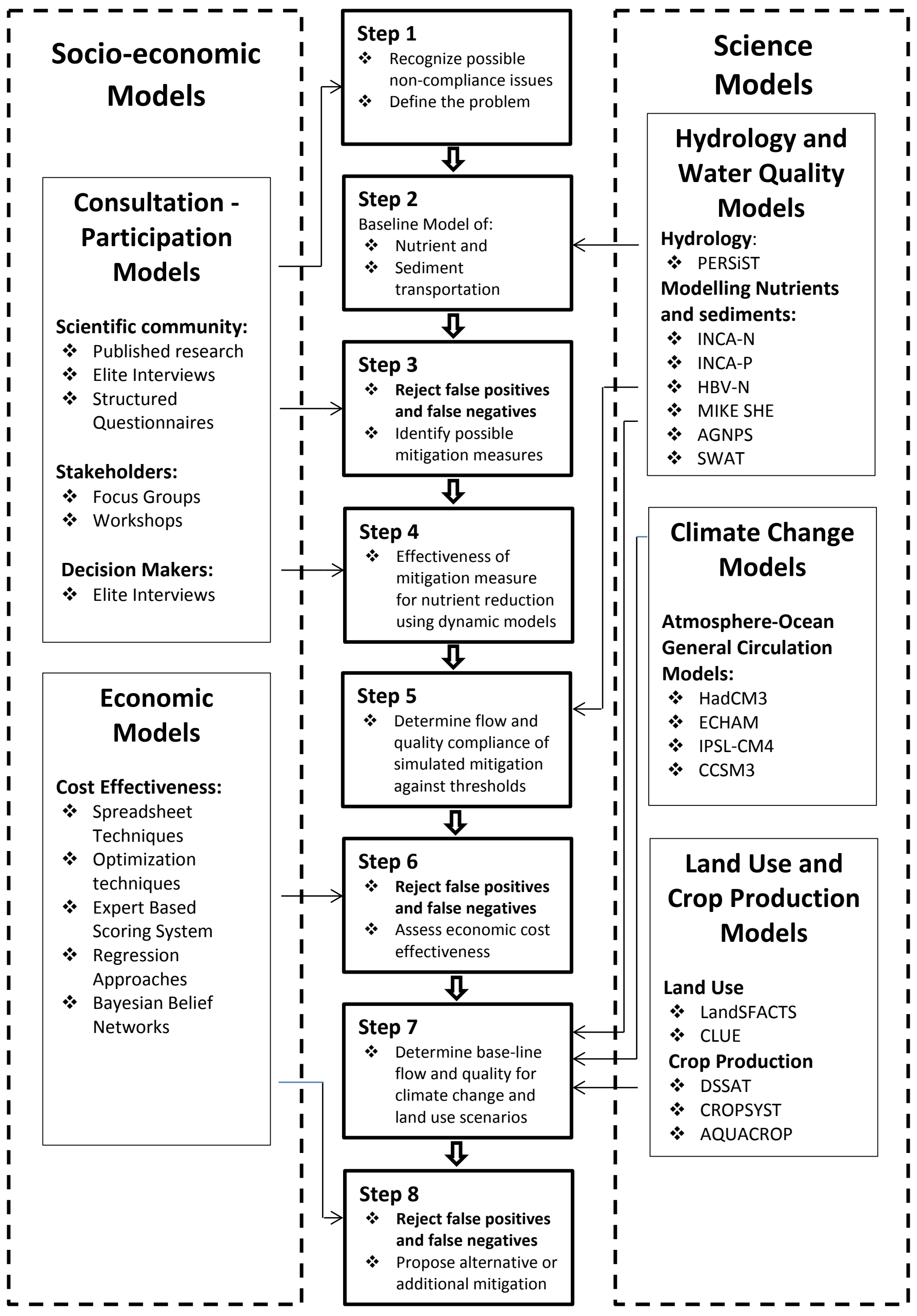


Figure 2. The eight step decision process integrating socio-economic and science models. 


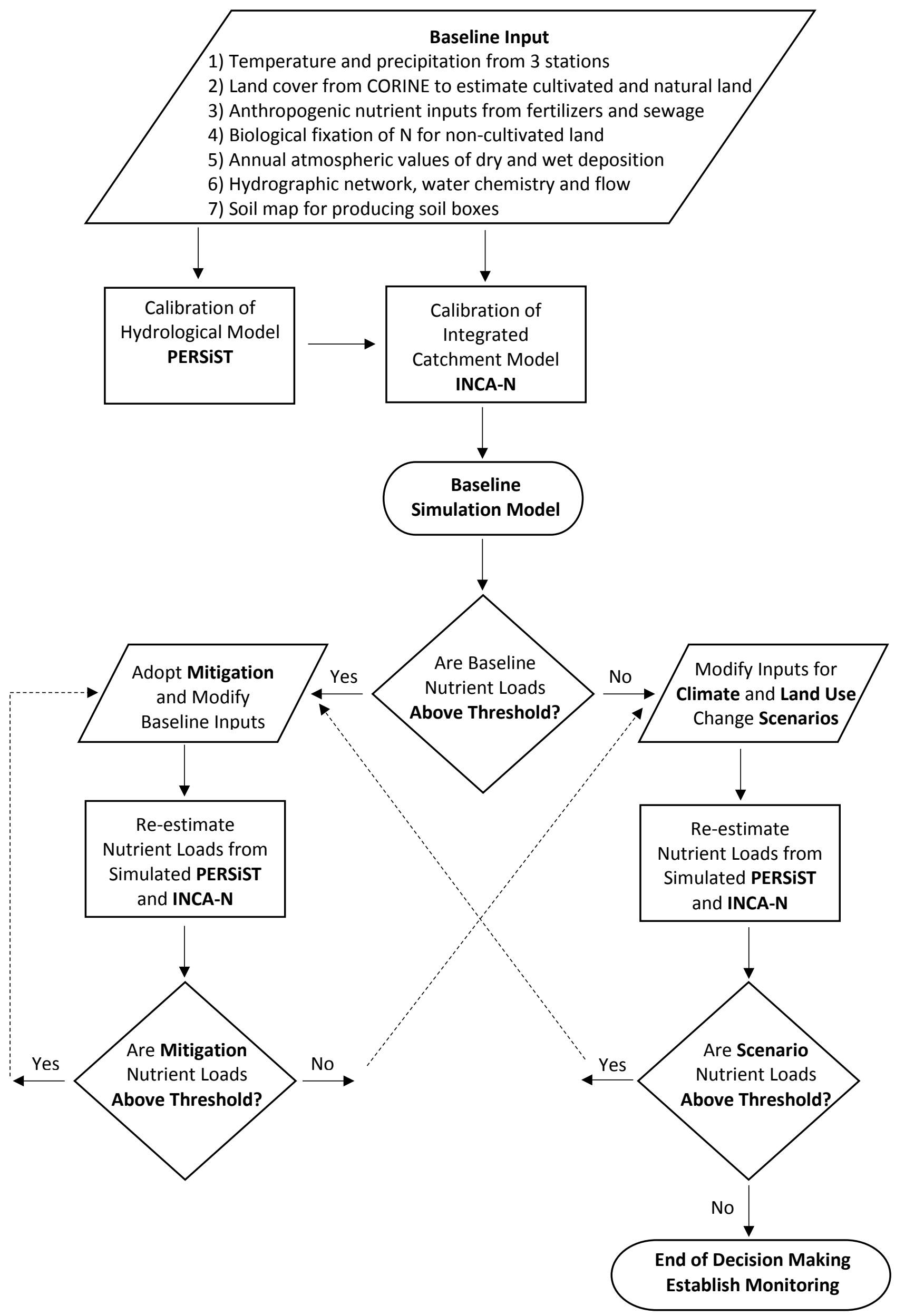


Figure 3. A flowchart of the baseline modelling, mitigation and simulation scenarios for the Louros catchment. 

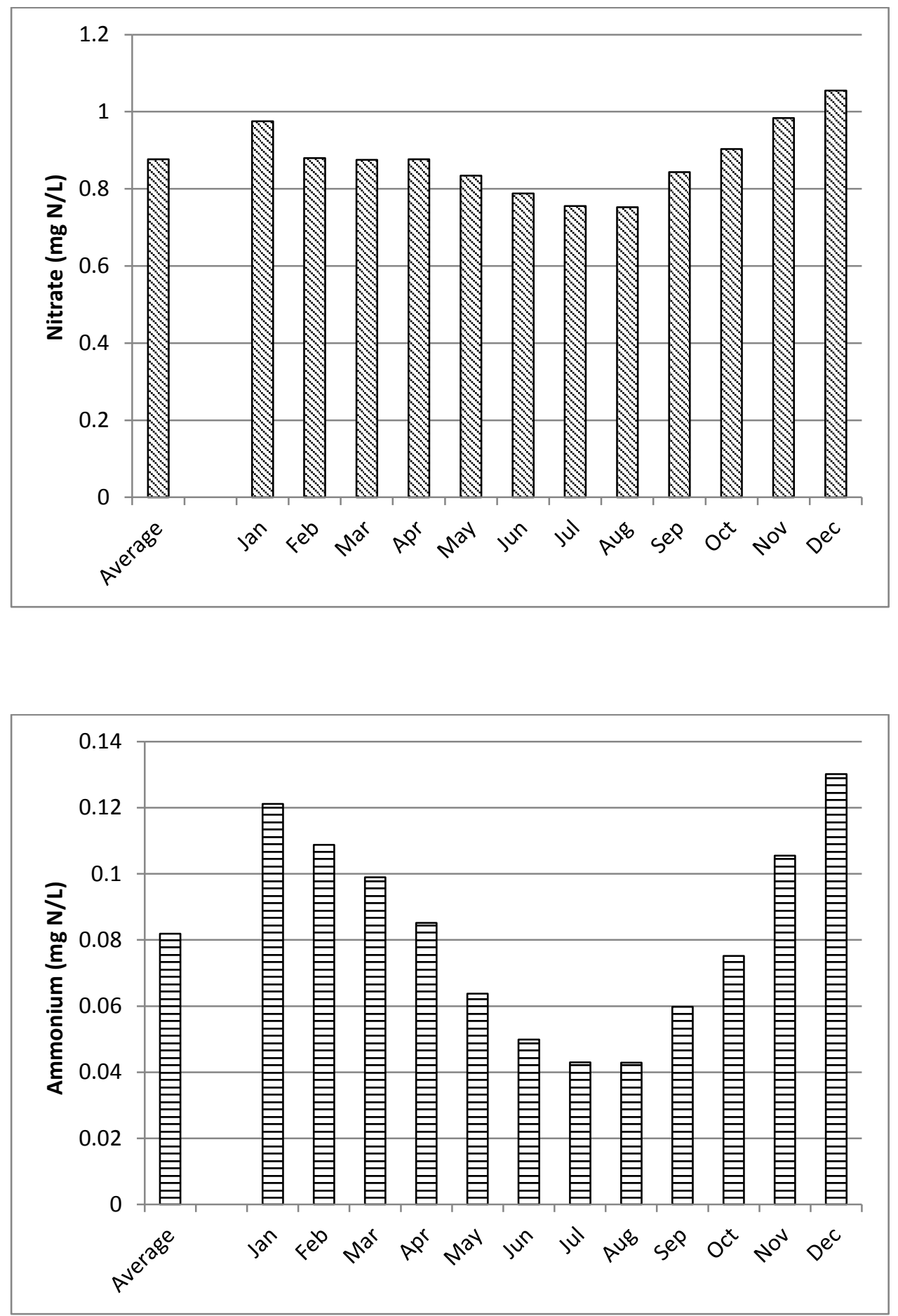


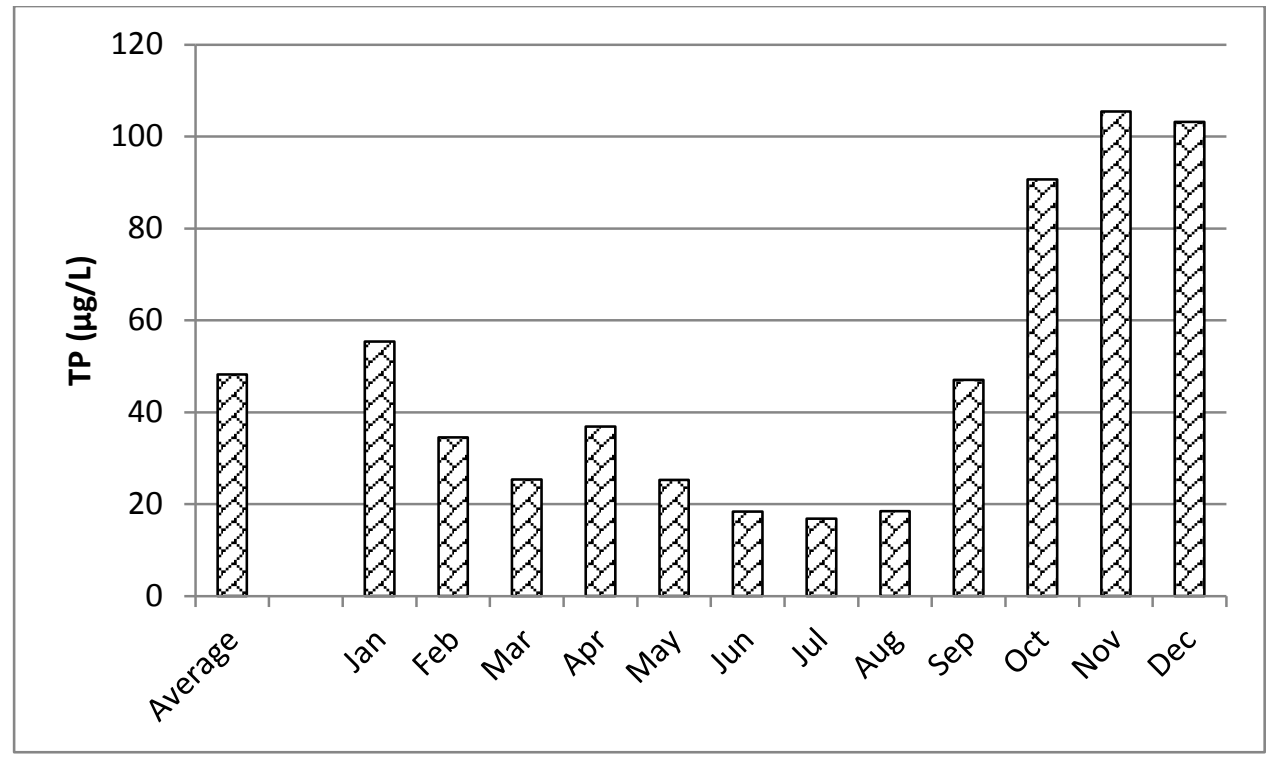

Figure 4. Baseline simulation of average and monthly nitrate, ammonium and Total Phosphorous (TP) concentrations. 
Table 1. The emergence and indicative underlying reasons of false positive and negative decisions in the design and implementation of agroenvironmental programs.

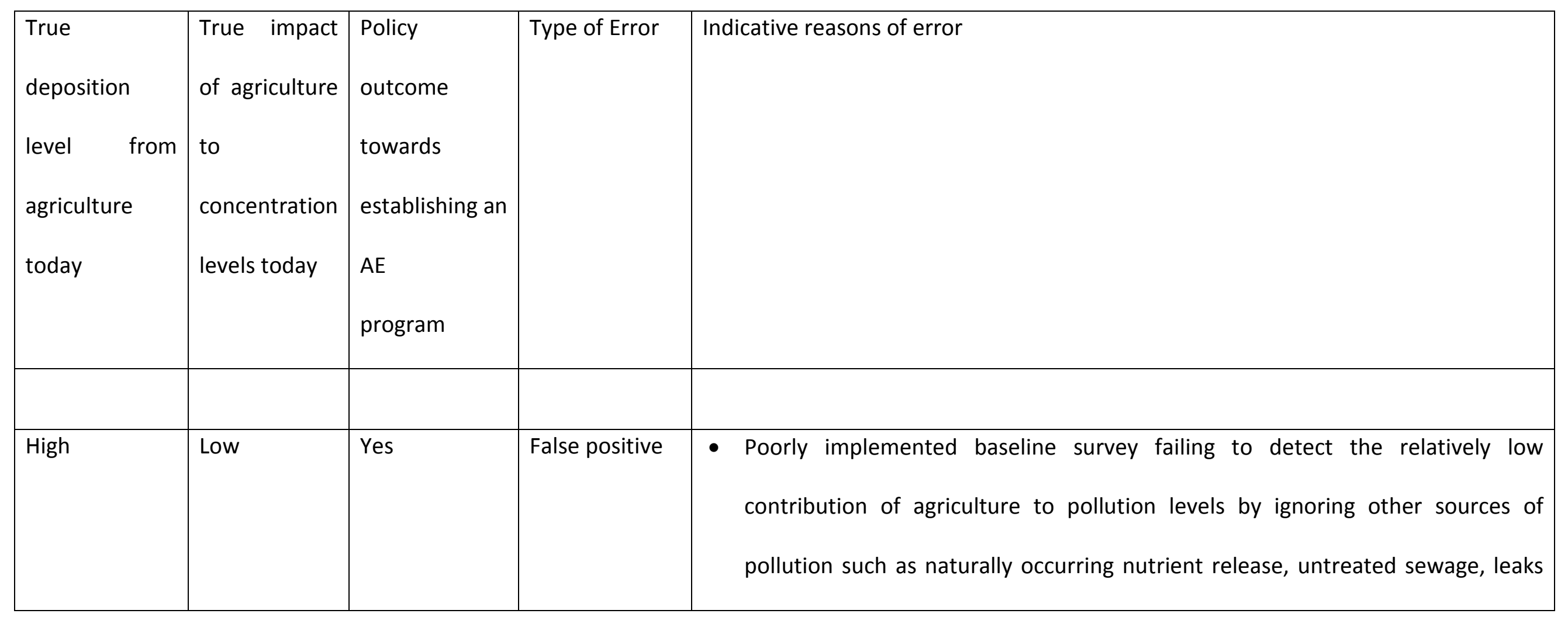




\begin{tabular}{|c|c|c|c|c|}
\hline & & & & $\begin{array}{l}\text { from poorly septic tanks, upstream fish farming, poorly treated industrial wastes, } \\
\text { etc. } \\
\text { - Failure to recognize the relatively low contribution of agriculture to pollution with } \\
\text { respect to other activities due to lack of consultation with local stakeholders on } \\
\text { the municipalities, illegal activities, etc. } \\
\text { - Failure to model the deposition-transportation-concentration relationship which, } \\
\text { due to abiotic or biotic reasons (existence of underground water reservoirs, soil } \\
\text { conditions favouring high denitrification, deposition at river banks, high plant } \\
\text { uptake, etc) results to the low contribution of agriculture to pollution }\end{array}$ \\
\hline High & Low & No & None & \\
\hline High & High & No & False negative & $\begin{array}{l}\text { - Poorly implemented baseline survey failing to detect high deposition levels and } \\
\text { attributing the observed high concentration levels to non-agricultural sources }\end{array}$ \\
\hline
\end{tabular}




\begin{tabular}{|c|c|c|c|c|}
\hline & & & & $\begin{array}{l}\text { - Failure to recognize high deposition levels due to lack of consultation with local } \\
\text { stakeholders on, for example, market price or policy transmitted incentives for } \\
\text { the use of excess fertilization, or lack of information on widely adopted bad } \\
\text { agricultural practices } \\
\text { - Failure to model the direct deposition-transportation-concentration relationship }\end{array}$ \\
\hline High & High & Yes & None & \\
\hline Low & Low & Yes & False positive & $\begin{array}{l}\text { - Poorly implemented baseline survey failing to detect low pollution levels and their } \\
\text { source, e.g., water samples collected during peak concentration end of summer } \\
\text { - Failure to recognize the relatively low deposition rates and low contribution of } \\
\text { agriculture to pollution due to lack of knowledge of e.g., specific, locally adapted } \\
\text { low-input agro-systems } \\
\text { - Failure to model the deposition-transportation-concentration relationship }\end{array}$ \\
\hline
\end{tabular}




\begin{tabular}{|c|c|c|c|c|}
\hline Low & Low & No & None & \\
\hline Low & High & No & False negative & $\begin{array}{l}\text { - Poorly implemented baseline survey failing to detect that despite low deposition } \\
\text { rates, very bad farming practices (time of application, irrigation methods, etc.) o } \\
\text { excess water abstraction for non-agricultural uses may lead to high nutrien } \\
\text { concentration in a possibly very unstable water ecosystem } \\
\text { - Failure to recognize the relatively low deposition rates but high impact o } \\
\text { agriculture to pollution due to lack of knowledge on e.g., local water managemen } \\
\text { practices that caused irreversible interventions leading to low water circulation } \\
\text { low water oxygenation, high solar radiation, etc. } \\
\text { - Failure to model the high impact of low deposition rates on concentration levels }\end{array}$ \\
\hline Low & High & Yes & None & \\
\hline
\end{tabular}


Table 2. Simulated nutrient concentrations under the baseline and different climate change, land use change and combined scenarios.

\begin{tabular}{|c|c|c|c|c|}
\hline & $\begin{array}{l}\mathrm{N}-\mathrm{NO}_{3} \\
(\mathrm{mg} / \mathrm{l})\end{array}$ & $\begin{array}{l}\mathrm{N}-\mathrm{NH}_{4} \\
(\mathrm{mg} / \mathrm{l})\end{array}$ & $\begin{array}{r}\text { SRP } \\
(\mu \mathrm{g} / \mathrm{I})\end{array}$ & $\begin{array}{r}\text { TP } \\
(\mu \mathrm{g} / \mathrm{I})\end{array}$ \\
\hline Baseline & 0.88 & 0.08 & 43.2 & 48.2 \\
\hline \multicolumn{5}{|l|}{ Agro-environmental Mitigation Measures } \\
\hline Mitigation 1 & 0.86 & 0.08 & 31.4 & 36.5 \\
\hline Mitigation 2 & 0.86 & 0.08 & 30.0 & 35.1 \\
\hline \multicolumn{5}{|l|}{ Climate and Land Use Changes Scenarios } \\
\hline Climate Change Best Scenario (KNMI+B1) & 0.86 & 0.07 & 42.8 & 48.8 \\
\hline Climate Change Worse Scenario (Hadley+A2) & 0.89 & 0.08 & 43.7 & 50.6 \\
\hline CAP Induced Land Use Change at $25 \%$ & 0.86 & 0.08 & 31.4 & 36.5 \\
\hline CAP Induced Land Use Change at $30 \%$ & 0.86 & 0.08 & 30.1 & 35.2 \\
\hline \multicolumn{5}{|l|}{ Scenarios from Combined Changes } \\
\hline Mitigation 2 and Climate Change (KNMI+B1) & 0.84 & 0.07 & 29.1 & 35.4 \\
\hline Mitigation 2 and Climate Change (Hadley+A2) & 0.87 & 0.08 & 29.9 & 37.5 \\
\hline CAP Land Use Change at $30 \%$ and Climate Change (KNMI+B1) & 0.84 & 0.07 & 29.4 & 35.1 \\
\hline CAP Land Use Change at $30 \%$ and Climate Change (Hadley +A2) & 0.87 & 0.08 & 30.6 & 36.8 \\
\hline
\end{tabular}

Source: Authors' estimates from INCA-N and INCA-P simulations. 
Table 3. Estimates of the average mitigation cost in the Louros watershed, Greece.

\begin{tabular}{|c|c|c|c|c|c|c|c|c|}
\hline \multicolumn{9}{|c|}{ A. Average estimates of fertilizer abatement under Mitigation 1} \\
\hline & & $\mathrm{N}-\mathrm{Kg} / \mathrm{ha}$ & $\mathrm{P}-\mathrm{Kg} / \mathrm{ha}$ & $\mathrm{N}-\mathrm{Kg} / \mathrm{ha}$ & $\mathrm{P}-\mathrm{Kg} / \mathrm{ha}$ & Cost (€/ha) & $\mathrm{N}$ & $\mathrm{P}$ \\
\hline Corn & 3,306 & 240.0 & 200.0 & 117.0 & 97.5 & 521.6 & 4.5 & 5.4 \\
\hline Medic & 4,009 & 80.0 & 100.0 & 35.0 & 43.8 & 437.2 & 12.5 & 10.0 \\
\hline Citrus & 2,093 & 300.0 & 40.0 & 75.0 & 10.0 & 538.1 & 7.2 & 53.8 \\
\hline \multicolumn{9}{|c|}{ B. Average estimates of nutrient concentration abatement under Mitigation 1} \\
\hline & Area (ha) & \multicolumn{4}{|c|}{ Simulated average concentration } & & & \\
\hline
\end{tabular}




\begin{tabular}{|c|c|c|c|c|c|c|c|c|}
\hline & & \multicolumn{2}{|c|}{ at baseline } & \multicolumn{2}{|c|}{ after mitigation } & $\begin{array}{r}\text { Cost of } \\
\text { mitigation }(€)\end{array}$ & \multicolumn{2}{|c|}{$\begin{array}{r}\text { Average Abatement Cos } \\
{[€ /(\mu \mathrm{g} / \mathrm{l})}\end{array}$} \\
\hline All & 9,745 & 0.88 & 48.2 & 0.86 & 36.5 & $4,825,061$ & 301,566 & 412,398 \\
\hline
\end{tabular}

Source: Authors' estimates from the RICA/FADN database, agronomic information and Focus Groups with stakeholders. 
